\title{
Research on Costume Ideology of the Pre-Qin Period from Perspective of Chu Ci
}

\author{
Chunguang Ren ${ }^{1} \&$ Xiaoming Yang ${ }^{1}$ \\ ${ }^{1}$ College of Humanities, Donghua University, Songjiang, Shanghai, China \\ Correspondence: Xiaoming Yang, College of Humanities, Donghua University, Songjiang, Shanghai, 201620, \\ China. E-mail: ynide@sina.com
}

Received: March 3, 2020

Accepted: March 13, 2020

Online Published: March 30, 2020

doi:10.5539/ass.v16n4p59

URL: https://doi.org/10.5539/ass.v16n4p59

\begin{abstract}
$\mathrm{Chu} \mathrm{Ci}$ is a collection of poems created by Qu Yuan. It combines the folk songs of the ancestors of the Yangtze river valley with ancient myths and legends, and has a strong local color and unique artistic style. Through the description of costumes in $\mathrm{Chu} \mathrm{Ci}$, we can find the formation, development and connection between costume ideology in the pre-Qin period and the ancient Chinese conception of nature, which has a significant influence on the formation of ancient Chinese philosophy and traditional clothing culture.
\end{abstract}

Keywords: the Pre-Qin Period, $\mathrm{Chu} \mathrm{Ci}$, costume ideology, clothing culture

The shape and system of costume in the pre-Qin period laid the foundation for the development of costume in ancient China. Clothing is the product of the material and spiritual life of human beings. Different clothing in different dynasties and periods is a representation of their social culture. Through the differences in the shape and structure of clothing, the development of social textile production in different times can be explored.

\section{Dress Ideology of the Pre-Qin Period and Five Elements Theory}

\subsection{Color of Clothes in Pre-Qin Period}

Each dynasty in the pre-Qin period had its own special respect for the color of clothing, Yu worships earth color, Xia worships wood color, Yin worships gold color, Zhou worships fire color, the different colors of different dynasties, which was not only related to aesthetics, but also related to national politics. Color was not only a symbol of national power, but also represented class differences. In addition, the colors favored by each dynasty in the pre-Qin period were also related to the Chinese theory of the five elements, which refers to the five elements of gold, wood, water, fire and earth. The ancients believed that these five elements were mutually reinforce and neutralize each other.

\subsection{Five Elements Theory and Five Colors}

The five elements represented the five colors, and the five colors represented the five virtues. The theory of the five virtues originated from the theory of the five elements. In the spring and autumn period, Zou Yan divided the world into five parts. He used the principle of the five elements of gold, wood, water, fire and earth to reveal the rule of the change of historical dynasties and brought the theory of the five elements into the political field. Yellow was honored in the Yellow Emperor's period, cyan was honored in the Xia Dynasty, white was honored in the Shang Dynasty, and red was honored in the Zhou Dynasty. To wood for virtue, advocating cyan, To soil for virtue, advocating yellow; Gold for virtue, advocating white; Fire for virtue, advocating red; To water for virtue, advocating black. The ancestor of the Chinese nation is the yellow emperor. The Chinese civilization originated in the Yellow River valley. Since the Han Dynasty, yellow was revered by the emperor and gradually became the special color of the son of heaven. The first ancestor of the Chinese nation was the Yellow emperor, and the Chinese civilization originated in the Yellow River valley. Between heaven and earth the identity of the son of heaven is the most noble, the highest status, so, the color of the five elements to yellow as noble. Since the Han Dynasty, yellow was revered by the emperor and gradually became the special color for the emperor's clothing (Huang, 2007). The theory of five elements is the cosmology of the ancient Chinese, which has a profound influence on the development of ancient Chinese philosophy. 


\subsection{Establishment of the Pre-Qin Costume System}

The Shang Dynasty period was the formation stage of the costume system in ancient China. Fragments of oracle bone inscriptions unearthed in the Shang Dynasty reveal many textile-related Chinese characters, which can reflect the prosperity of the textile industry in the Shang Dynasty. The Zhou Dynasty was the period when China's dress system was formally established. To emphasize the difference in rank and status, the Zhou Dynasty established a complete dress system. From then on, Chinese costume had the meaning of "ritual", which was brought into the category of social etiquette and law by the ruling class, and became the mark of distinguishing the status, dignity and rank (Su, 2013).

\section{Uniqueness of Jing-Chu Culture and Costume Description of Chu Ci}

In the pre-Qin period, the Chu people in the Jiang-Han region expanded their territory by five thousand li and founded the country for eight hundred years. For a long time, the Chu people absorbed the cultures of the Yangtze river valley and the southern regions. From the western Zhou Dynasty to the spring and autumn period, the Jing-Chu culture with unique regional characteristics gradually formed. The uniqueness of Jing-Chu culture lies in the interaction of heaven, earth, people, gods, witches and ghosts. Worship ghosts and rational simple, that is beautiful and romantic and unyielding, It is this seemingly contradictory but perfectly integrated cultural characteristics that gave birth to $\mathrm{Chu} \mathrm{Ci}$ and the classic of mountains and seas. The emergence of $\mathrm{Chu} \mathrm{Ci}$ has something to do with the superior natural geographical environment of mountains and rivers and the unique background of Jing-Chu culture. Guo Mo ruo believed that the natural environment of the state of Chu was responsible for $\mathrm{Qu}$ Yuan's magnificent, strange and beautiful prose, one of the reasons for his magnificent, upright and charming personality (Xu, 2015).

The women in the Book of Odes often appeared in the fields, mulberry forest and other places of labor, while the women in $\mathrm{Chu} \mathrm{Ci}$ often appeared in Wu Shan mountain, Xiang Jiang river, palace banquets, sacrificial occasions. Jing-Chu culture is obviously different from Shang and Zhou Dynasty culture, which is reflected in its combination of poetry, music and dance. Through the description of clothes and ornaments in $\mathrm{Chu} \mathrm{Ci}$, we can see that the clothes of Chu people are gorgeous and colorful. The people of Chu were fond of witchcraft. In the poems of "conjuring the spirits", "grand recruit" and "nine songs", we can see mythological figures, sorceress and mountain ghost. They are in solemn and mysterious places of worship, dressed in colorful costumes, to the music, step the rhythm, singing and dancing, take turns to appear. Through the interpretation of poems in $\mathrm{Chu} \mathrm{Ci}$, we can clearly see the characteristics of "man and god mixed" in Chu culture. The distinctive regional characteristics of Jing-Chu culture made it occupy an important position in the Chinese national culture, which had a far-reaching impact on the Chinese culture of Qin and Han Dynasties and even later generations.

\section{Zhou Dynasty Clothing Characteristics and Formation Reasons}

\subsection{Clothing Characteristics of Zhou Dynasty}

Zhou Dynasty was an era that paid attention to men's aesthetics, when the status of women gradually declined and the patriarchal society rose. Reflected on the dress, that is, the male dress is gorgeous and complicated, the female dress is quietly elegant and dignified. It can be clearly seen from the book of Odes that the clothing characteristics of the Zhou Dynasty are obviously different from those of other dynasties. In the Zhou Dynasty, the production process of male clothing was complicated and colorful, while female clothing was mainly plain and elegant.

\subsection{Reasons for Formation of Clothing Characteristics in Zhou Dynasty}

1) Natural concept of "unity of heaven and man" in Zhou Dynasty

The characteristics of male clothing in the Zhou Dynasty were similar to the behavior of males in nature to display gorgeous fur to attract females, both to display male beauty. For example, the word "beauty" in the book of Odes, unlike other dynasties, refers not to a woman but to a strong man.

2) Chain of causality brought by the rise of patriarchal society

The Zhou Dynasty is the formation period of the ritual system, and clothing has been incorporated into the social moral system. The etiquette of the Zhou Dynasty was closely related to the dress system. The idea of dress in Zhou Dynasty was to use dress to represent virtue and virtue to represent all things. As the social status of men goes up, the social status of women goes down, therefore, plain color is endowed with the moral meaning of female virtue and chastity in social concept.

3) Original female aesthetic remains

In the poem of the book of Odes, there is a special aesthetic horizon, that is, the visual aesthetic of men. It is to 
take the female perspective as the aesthetic subject, and the male as the aesthetic object. The reason is the remains of ancient matrilineal culture, so that the social aesthetics of Zhou people still has the Angle of matrilineal culture.

\section{Clothing Culture of Chu during the Spring and Autumn Period}

In the spring and autumn period and the warring states period, costume culture of Chu was as unique as that of Jing-Chu culture. According to the description in the $\mathrm{Chu} \mathrm{Ci}$, the people of $\mathrm{Chu}$ were dressed in gorgeous and exquisite costumes, often using exotic flowers and herbs as costumes, with a high crown on the head, a long sword on the body, vanilla and jade.

The early clothing styles of Chu were similar to those of the Shang and Zhou dynasties. During the warring states period, the clothing styles of the state of Chu changed. They began to wear broad bands around the waist and thin and long clothes. The fabric is gorgeous, the colors are colorful, the clothes are full of patterns and patterns, collar sleeve skirt waist hem for the curve form, design is also decorated for the curve (Zhu, 2001).

If the clothing of Chu people is different from that of central China, it is from different appreciation of beauty. Chu people were fond of witchcraft, and this religious worship was reflected in the patterns of clothing, with various natural and animal patterns appearing. These patterns were not only used for decoration, but also the embodiment of Chu people's worship of nature.

The author thinks that Chu people's dress thoughts and ideas are worship of sorcery and romanticism, and formation of the Chu people's dress thoughts and ideas is related to the unique mountain and river landforms and the humid and rainy climate of Chu. The mist-shrouded Wu Shan mountain and the meandering Xiang Jiang river gave birth to the seemingly contradictory and harmonious characteristics of the romance and rationality of Chu people. Under the representation of tender and gorgeous costumes of Chu people, it is the patriotic feelings interwoven with rationalism and romanticism.

\section{Costume Ideology of the Pre-Qin Thinkers}

\subsection{Confucian Thoughts and Ideas on Costume}

Confucianism advocates deny self and return to propriety, loyalty, filial piet chastity and righteousness. Confucianism is reflected in the clothing, not only to maintain the etiquette, but also to emphasize the hierarchy of the emperor and ministers, the order of the young and the old, men and women are different. Confucianism not only attaches importance to the aesthetic feeling of outer clothing, but also requires the inner and outer harmony of the gentleman. Clothing represents the outside, thought represents the inside. Confucius thought that a gentleman should be both inside and outside the practice, refined. Follow the way of king Yao and Shun, follow the system of king Wu of Zhou, bound by courtesy.

Confucius included clothing in the ethical category, emphasizing the difference between men and women. Clothing should not only conform to the status, but also be suitable for the occasion. The Confucian thought that jade represents the inner temperament and accomplishment of a gentleman. As a gentleman personality should be like jade personality is gentle, make people feel kind, words and thoughts to meet the moral requirements of a gentleman. Only in this way can we embody the unity of social ethics and personal culture.

Xun $\mathrm{Zi}$ elevated the dress to the principle of governing the country, and emphasized the role of etiquette in the dress. He thought that a uniform dress system should be established to distinguish people's social status, People's identity is different, class is different, rich and poor are different, should try to distinguish from dress. Compared with Confucius and Mencius, Xun Zi's view of hierarchical clothing is more in line with the interests of the ruling class, It has a profound influence on the development of Chinese costume culture in Han dynasty and later generations (Hua, 2001).

\subsection{Taoist Thoughts and Ideas on Costume}

Taoist thought of clothing is to pay attention to the inner cultivation of people, ignoring the appearance. Burlap is an ancient civilian clothing, rough texture. Jade was an ornament worn by the ruling class. Lao-tzu said that even if the saint wore sackcloth, his heart should be as gentle as jade Lao-tzu and Confucius are different in their views of both internal and external cultivation. He believes that the inner beauty of people refers to the cultivation of moral character, just like jade, even if you wear coarse clothes, but also can not cover up the brilliance of the inside.

According to Chuang-tzu, complicated etiquette can only restrain people's nature and eventually make people lose themselves. People's spirit and appearance, to be detached, not to be disturbed by external things. From the perspective of social ethics, Chuang-tzu believed that clothing is deceptive, too much emphasis on external 
decoration, people will rely on the influence of clothing, resulting in inner spirit is bound by the external, and into the situation of not free. In Chuang-tzu's opinion, if the costume system based on traditional etiquette is considered as civilization, then civilization is not as civilized as uncivilized, perhaps uncivilized is the best civilization (Zhang, 2017). Chuang-tzu thinks that from nothing to something, from something to nothing, all should conform to the nature, Chuang-tzu's spiritual world and its Costume Ideology are dialectical unity, which is the reflection of Taoism's detached thought.

\subsection{Mohism Thoughts and Ideas on Costume}

Mohism's Costume Ideology is pragmatism, clothes must always be warm, and then to further the requirements of gorgeous. Mohism defends the interests of craftsmen and workers, while Confucianism defends the interests of the ruling class. Confucius advocated both internal and external maintenance, and the unity of clothing man, while Mo-tzu advocated quality before writing, based on the practical. Confucianism stresses the etiquette indoctrination. Mohist advocates equality and universal love. As a matter of fact, Mohism's dress thoughts of frugality and equality are opposite to Confucian's dress thoughts of respect and inferiority.

Mo-tzu believed that clothing is first practical, and then the pursuit of beauty, there is no need to be too gorgeous. He thought, Confucius beguiled people with pomp and decoration, and used complex procedures to show etiquette. Although Confucianism has a lot of knowledge, it does not allow people to talk about state affairs. For the young, Confucian etiquette is too complex, its way can't be used to govern the country, learning can't teach the people. In the spring and autumn period and the warring states period, the productivity level was low, and the war caused the people to live in poverty. Instead of trying to restrain people with complicated etiquette and hierarchy, it is more practical to feed and clothe them. Mo-tzu was the only one who reflected the interests of the people at the bottom. Mohism is the most distinct doctrine against aristocracy (Sun, 2001). The practical and thrifty clothing thought advocated by Mo-tzu, though with historical limitations, However, it is dialectically united with his idea of universal love and non-attack.

\subsection{Legalist Thoughts and Ideas on Costume}

Legalist advocates strict legal governance in troubled times, and its idea of dress is to value the essence and abhor decoration. According to Han Fei Zi, etiquette exists as a social behavior norm that restricts the public, is the external expression of people's inner feelings, and cultural talent is the modification of the inner nature. The gentleman should respect the heart and abandon the outside, like the essence and hate decoration. Those inner feelings which need to be explained by external expression are disgusting. That which depends upon the modification of appearance to illuminate the inner nature is decayed (Zhang, 2001). According to Han Fei Zi, the essence of beauty does not need to be decorated, and those who need to be decorated are beautiful because their quality is not beautiful (Hua, 2001).

From this point of view, there are some similarities between legalism and Mohism, both of which are opposite to the Confucian view of clothing. However, legalist and Mohist were slightly different. Mohism advocated equality, and the clothing was mainly about warmth, without distinguishing the beauty and ugliness in essence. The essence of the dress thought of the legalist family is to serve the ruling class. It thinks the essence is beautiful, the modification is more beautiful. The essence is ugly, embellishment is useless.

In the era of the legalists, the struggle between the warring states was more and more intense. No matter the courtesy of Confucianism, the universal love of Mohism, the natural way of Lao-tzu, obviously, costume ideology advocated by the pre-Qin scholars were not suitable, and it was impossible to stop the war. It was impossible for them to guide vassal states to pacify wars by using costumes as a code of etiquette. Only strict codes could govern the country. Although the dress thought of the legalist school and the Mohist were the same, they were finally defeated by the Confucian. However, the costume thoughts of each of them had their own merits laid a foundation for later generations of Taoists to be far away from the secular culture, and for the ranger culture of Mohism, which had a profound influence on the ancient Chinese traditional culture.

\section{Transmutation of Zhao's Costume Ideology}

In the history of Chinese costume development, the state of Zhao, one of the seven heroes of the warring states period, is famous in history for its king $\mathrm{Wu}$ ling of Zhao, who broke the traditional costume system and carried out the costume reform of shooting on horse in Hu dress (Zhao, 2004).

During the warring states period, although the costumes and customs of various vassal states had their own characteristics, the costumes were similar in shape and structure. The head wears the high crown, the broad robe big sleeve, is helpful for the ethical and educational thought to carry out. Cultivated the wind of modest gentleman, even become the representative of China's advanced culture. This noble quality should be inherited 
forever in the country of the gentleman. However, this style of dress was not suitable for the military of the state of Zhao, at that time, the state of Zhao had been harassed by some tough nomads such as Eastern barbarian and Huns in the north. Because the clothing is not suitable for running combat, and can't defend and pursuit. To enrich the country and strengthen the army, to resist the intrusion of various nationalities in the western regions, King $\mathrm{Wu}$ ling of Zhao initiated the first reform in Chinese costume history, shooting on horse in Hu dress, he put forward costume ideology that clothes should be practical and convenient.

Clothing of Hu nationality refers to clothing of ethnic minorities in the northern and western regions of ancient China. Shooting on horse in Hu dress, is to imitate the shape and system of Hu people's clothing, so that the army is conducive to fighting on horseback. King Wu ling of Zhao changed the style of clothes under the coat from the western Zhou dynasty to short clothes with narrow sleeves and crotch trousers. The styles of hats and belts and shoes of $\mathrm{Hu}$ nationality are also used. Zhao state topography is prominent, the mountains and hills are very many. Affected by the roads, the horse-drawn chariots of the central plains army were not suitable for the terrain of the state of Zhao. Compared with the northern barbarians, who wore short jackets with narrow sleeves and fought with great mobility. Although the impact force and speed of Zhao army exceeded the northern barbarians army, it was difficult to enter the mountainous and hilly areas, resulting in slow action, which was not conducive to the situation of fighting. The clothing reform of king Wu ling of Zhao firstly started from the military system reform (Yu, 2015). Based on realistic political factors, his starting point is consistent with Mohism, which is practical utilitarianism, indicating that clothing has been transformed from maintaining ritual to pragmatism.

\section{Conclusion and Suggestions}

From the primitive society into the class society, clothing was used by the ruling class to distinguish the status of the hierarchy. Zhou dynasty to rule the country, everything must conform to the etiquette, the use of clothing is also affected and restricted by ethics. During the spring and autumn period and the warring states period, the Zhou dynasty was weakened by the powerful vassal states. Among the vassal disputes, war, resulting in the collapse of rite. It was an era of frequent wars and turbulence, and an era of unprecedented prosperity of academic thought. The hundred schools of thought regard clothes and clothing as the medium of representing rank and dignity, and are closely related to the way of governing the country and the art of conducting the world. The costumes and customs of various states are widely different, and the ideas and views of different schools of thought collide with each other fiercely, Different schools of thought contend with each other. Confucianism maintains hierarchy and constrains people's thoughts with complicated etiquette. Taoist viewed the society from a hidden perspective. Lao-tzu returned to his original simplicity in poverty. Chuang-tzu world free and unfettered things I two forget. The law governs men by cruel laws. Only mohism advocates equality and universal love.

In the warring states period, there was a fierce war of annexation. In order to seek a way to become a powerful country and improve the productive and military ability of the people, king Wu ling of Zhao initiated the reform of clothing. The so-called not to break, not to stand, since you have broken, will stand. This reform of king Wu ling of Zhao was not only a challenge to the traditional system of rites, but also an ideological revolution to break the shackles of traditional thinking. Time travel through a thousand years, the Qing dynasty Qianlong period of Wei Yuan, as modern China opened its eyes to see the world's first prophets, in his book Hai Guo Tu Zhi proposed to learn the west's advanced military technology to seek a way to resist foreign enemies. This is the inheritance of the thought of shooting on horse in Hu dress. The reform of clothes initiated by king Wu ling of Zhao, which seemed to be against the etiquette system, not only changed the social customs of Zhao. It has a strong impact on the clothing system formed since the western Zhou dynasty and has a far-reaching impact on the development of clothing system in the Qin and Han dynasties and later generations.

\section{References}

Hua, M. (2001). Clothing and Chinese culture (p. 62). Beijing: People's Publishing House.

Hua, M. (2001). Clothing and Chinese culture (pp. 35-46). Beijing: People's Publishing House.

Huang, Q. (2007). History of Chinese costume painting (pp. 2-8). Tianjin: Baihua Literature and Art Publishing House.

$\mathrm{Su}$, S. (2013). Chinese interesting clothing culture (p. 21). Beijing: Beijing University of Technology Press.

Sun, Y. R. (2001). Interpretation of Mo-tzu (p. 3). Beijing: Zhonghua Book Company.

Xu, Z. X. (2015). ChuCi compilations (p. 11). Shanghai: Shanghai Ancient Books Publishing House.

Yu, K. (2015). History of the warring states period (p. 33). Shanghai: Shanghai People's Publishing House. 
Zhang, Z. C. (2001). Chinese clothing culture (Vol. 1, p. 257). Beijing: China Textile Press.

Zhang, Z. C. (2017). Chinese costume culture (p. 141). Beijing: China Textile Press.

Zhao, C. (2004). Five thousand years of Chinese costume culture (p. 42). Jinan: Jinan Press.

Zhu, H. P. (2001). Chinese costume history (p. 89). Zhenzhou: Zhongzhou Ancient Books Publishing House.

\section{Copyrights}

Copyright for this article is retained by the author(s), with first publication rights granted to the journal.

This is an open-access article distributed under the terms and conditions of the Creative Commons Attribution license (http://creativecommons.org/licenses/by/4.0/). 